\title{
Homeopathic diagnosis and treatment of malaria in Kenya
}

\author{
Martien Brands and Suzanne van Berkel \\ Centre for Integrative Medicine, Amsterdam \\ School for Homeopathy, Amersfoort
}

Introduction. Homeopathy has been practiced since many years in Kenya, often by experienced and well trained practitioners, in several primary care clinics. But no systematic data collection has yet been made. We have chosen, after a feasibility study in 2012, some clinics to participate in this recording of daily practice data. We request the practitioners to record the data as used for therapeutic prescription in the practice, and to assess the effect of homeopathic prescriptions with disease-oriented and patient-oriented data. With these data it will be plausible to do further studies which involve the modification of treatment for research purposes. So this recording does not involve any change for the practitioners in their current way of delivery of care; it is rather a mirror of their activity so as to get an insight in their work. Relevance: Malaria has been selected for its impact on the health of large populations, both in the acute, short and recurrent, longterm form. The homeopathic treatment may be an option when other treatments are not available for reasons of safety (pregnant women) or affordability (price of conventional malaria drugs) or logistic reasons (access from remote villages). With the purpose of giving the population access to affordable health care, with a treatment that has been used a long time but has been investigated in only a few controlled studies. One study, under the supervision or the first author, has been done in Ghana showing comparable effects of homeopathy and the standard treatment at that time, chloroquine (van Erp and Brands 1996). As policies have changed since then, it is logical to compare in next studies homeopathy with the current antiparasitical treatments. In Kenya this is artemisine.

Aim: to record homeopathic practice data in Kenya. And thereby to provide the relevance for further pragmatic, randomized studies.

Rationale for personalized, immune-stimulatory treatment. For treating malaria we have two options: to attack the microorganism or reinforce the immune system; homeopathy falls within the latter approach. Recent studies show effects of several homeopathic medicines on the immune-function in both plant, animal and human models (cf reviews of Bellavite et al 2006, 2007, and the Health Technology Assessment by Börnhoft and Matthiesen 2011). This state of the art shows the relevance of testing the effects of immunetargeting homeopathic drugs in a parasitical disease, where resistance development to microbial metabolismtargeting antiparasitical drugs is an important barrier for many people to acquire a better health status. To influence the immune system, two conditions need to be met

- the stimulus needs to match the state of the immune system itself, which has specific changes in its composing messengers that express in clinical symptoms Therefore, low concentrations of active agents are appropriate to interact with the minute concentrations of most immune agents. They function within a complex system which features non-linear relationships between stimulus and response (cf. Plsek and Greenhalgh 2001). 
- the stimulus is highly specific, i.e. it matches with the peculiarities of the individual patient. Recent simultaneous measurement of many agents, both on the level of genomics, proteomics and metabolomics (van der Greef 2005) show the changes in patterns of markers rather than in single markers; this confirms interindividual biochemical differences which are reflected in interpatient variation as assessed in homeopathic diagnosis.

Methods: First, a qualitative study of 50 cases has been done from the period of december 2013-january 2014. The data of symptoms (both classical malária plus the typical symptoms following homeopathic case taking) and the prescription strategies were coded and analysed with SPSS (Statistical Programme for Social Sciences). The latter includes: the choice of remedies, potencies, frequency and duration.

Second, an quantitative, open registration is done for patients arriving with malária to the clinics in the period of march until june 2014. The acute episodes of malaria are recorded; the recording therefore will include the data as in table 1 :

1. classical malaria symptoms

2. individual symptoms

3. if required the 'profile of sensitivity' is further assesed by the features on three levels: mental, general and local features

4. parasite counts before and after treatment

5. the scores on the Oridl (previously the Glasgow Homeopathic Hospital Outcome score, GHHOS) by two questions re. the main complaint and the overall impact of the treatment on well-being

The feasability of this recording was assessed taking into account the following items re: the quality of delivery of care

- the experience and training of the practitioners involved,

- the properness and privacy of the consultation rooms,

- the quality and storage of the medicines administered,

- the quality of the laboratory equipment for: parasite counts and eventual co morbidity (typhoid fever; amebiasis and other parasites)

- the accessibility of care regarding the fees asked from patients

Inclusion of

- all patients from five years and older, presenting symptoms suggesting malaria and with positive parasitology, at the clinics for homeopathic treatment.

- also in combination with other infectious disease, if malaria is confirmed at first consultation

\section{Exclusion of}

- all patients with feverish illnesses but with parasitologically confirmed absence of malaria infection. 
- patients with any symptoms of cerebral malaria, they are referred as usual to a nearby hospital for intensive care.

Protocol of the recording:

1. extraction from the clinical files of the data, recorded in Excel data base

2. data: demographic, clinical, laboratory, quality of life (Oridl)

3. drop out recording for followup

4. statistical analysis after coding of all data with SPSS. Non-parametric tests for symptom reduction and quality of life (Oridl).

As this is a naturalistic recording with no change in treatment policies from the usual care, no ethical clearance was required. The data in this study are however required to obtain ethical clearance for a future randomized pragmatic study.

Table 1: Malaric patient record

\begin{tabular}{|c|c|c|}
\hline Demographical data & $\begin{array}{l}\text { Name, gender, residence, data of } \\
\text { visit }\end{array}$ & \\
\hline \multirow[t]{3}{*}{ Clinical parameters } & Malaria symptoms & $\begin{array}{l}\text { Headache, fever, chills, joint } \\
\text { pains, lumber paravertebral pains }\end{array}$ \\
\hline & Individual symptoms & $\begin{array}{l}\text { Sensation/ type of pain } \\
\text { Modalities (factors that amel/agg } \\
\text { the main sensation) } \\
\text { Co-morbidity symptoms } \\
\text { Etiology (context of origin of } \\
\text { complaint) }\end{array}$ \\
\hline & Individual features: & Mental, general, local \\
\hline Laboratory tests & $\begin{array}{l}\text { Parasite count } 1+\text { until } 4+\text {, before } \\
\text { and after treatment }\end{array}$ & $\begin{array}{l}\text { Comorbidity: typhoid fever, } \\
\text { brucellosis, amoebiasis, others (eg } \\
\text { hookworm) }\end{array}$ \\
\hline Remedy & Potency, frequency, duration & \\
\hline Follow up: & $\begin{array}{l}\text { In one to two weeks; repeat/ adjust } \\
\text { diagnosis and treatment if } \\
\text { Positive count remains. }\end{array}$ & \\
\hline Effect of treatment: & 1. Parasite count & $\begin{array}{l}\text { 2. ORIDL - Outcome Related to } \\
\text { Impact on Daily Living }\end{array}$ \\
\hline \multicolumn{2}{|c|}{$\begin{array}{l}\text { ORIDL } \\
\text { Questions for every follow-up patient: } \\
\text { 1. Compared to how you were before your initial appointment, } \\
\text { what has been the overall effect of your treatment at this clinic } \\
\text { on your Main Complaint (the one you came to get treated)? } \\
\text { 2. Compared to how you were before your initial appointment, } \\
\text { what has been the overall effect of your treatment at this clinic }\end{array}$} & $\begin{array}{l}\text { +4 Cured / Back to normal } \\
\text { +3 Major Improvement } \\
\text { +2 Moderate improvement, } \\
\text { affecting daily living } \\
\text { +1 Slight improvement, no } \\
\text { effect on daily living } \\
0 \text { No change / Unsure }\end{array}$ \\
\hline
\end{tabular}


on your general Well-being?
-1 Slight deterioration, no effect on daily living -2 Moderate deterioration, affecting daily living -3 Major deterioration -4 Emergency condition

Keywords: malaria homeopathic diagnosis, homeopathic treatment, Kenya

\section{(cc) BY-NC-ND Licensed to GIRI}

Support: this study is supported by a grant from the Louise van Eeghen Foundation

Conflict of interest: authors declare there is no conflict of interest

Received: March 30 th 2014; Revised: May 10 ${ }^{\text {th }}$ 2014; Published: June $30^{\text {th }} 2014$

Correspondence author: Martien Brands ; martienbrands@telfort.nl.

How to cite this article: Brands M, van Berkel S. Malaria in Kenya. Int J High Dilution Res [online]. 2014 [cited YYYY

Month dd]; 13(47):93-96. Proceedings of the XXVIII GIRI Symposium; 2014 Jun 20-22; Sighisoara (Romania). GIRI; 2014;

Available from: http://www.feg.unesp.br/ ojs/index.php/ijhdr/article/view/720/696 